\title{
Analisis Jumlah Laser Dioda Terhadap Amplifikasi Daya Intensity Tunable Laser Pada Aplikasi Sumber Cahaya Pandu Gelombang Optik Berbasis Material Nonlinear
}

\author{
Ulan Sari $^{1)}$, Nur Abdillah Siddiq ${ }^{1)}$, Muhimmatul Khoiro ${ }^{1)}$, Achmad Syarif Hidayat ${ }^{2)}$, \\ Dwi Julianitasari ${ }^{1)}$
}

1 Departemen Fisika, Institut Teknologi Sepuluh Nopember

2 Departemen Teknik Fisika, Institut Teknologi Sepuluh Nopember

Email : siddiq.tf@gmail.com

\begin{abstract}
Nonlinear material becomes the key material of modern information and communication technology. Developments of Optoelectronic device such as ultrafast switching, high-capacity information modulation, optical logic gates, and power divider waveguides are the direct application of nonlinear materials. In the practice of utilizing nonlinear materials, light sources have a vital role. This is due to the amplification of the intensity of the light source can cause the appearance of nonlinear effects. During this amplification of light intensity is done through doped fiber amplifier (DFA). The price of EDFA on the market is quite expensive and the design of EDFA optical reinforcement system also requires a very high cost, including the procurement of tools and optical instruments used. In this study designed a device capable of intensifying intensity with relatively economical cost, using laser diode and wave superposition principle. In testing through the optical power meter, we have obtained the intensity value derived from 6 Visual Visual Fault Locator laser that is coupled using $1 x 8$ splitter. In the absence of phase control, the results obtained that the number of lasers that produce the greatest intensity is a combination of 3 lasers. Whereas, in the combination of 6 lasers, there is less power than 1 laser, this indicates that phase control becomes very important for constructive interference to occur.
\end{abstract}

Keywords: diode laser, side-by-side combining method, constructive interference, nonlinear material

\begin{abstract}
Abstrak: Material nonlinear menjadi material kunci atas teknologi komunikasi dan informasi modern. Perkembangan dunia optoelektronik seperti ultrafast switching, modulasi informasi berkapasitas tinggi, gerbang logika berbasis optik, dan pandu gelombang pembagi daya adalah aplikasi langsung dari material nonlinear. Dalam praktik pemanfaatan material nonlinear, sumber cahaya memiliki peran sentral. Hal ini disebabkan oleh amplifikasi intensitas sumber cahaya dapat menyebabkan munculnya efek nonlinear. Selama ini amplifikasi intensitas cahaya tersebut dilakukan melalui doped fiber amplifier (DFA). Harga EDFA di pasaran cukup mahal dan rancang bangun sistem penguatan optik EDFA juga memerlukan biaya yang sangat tinggi, termasuk pengadaan tools dan instrumen optik yang digunakan. Pada penelitian ini dirancang suatu alat yang mampu melakukan amplifikasi intensitas intensitas dengan biaya yang relatif ekonomis, yakni berbasis laser dioda dan menggunakan prinsip superposisi gelombang. Dalam pengujian melalui optical power meter, telah didapatkan nilai intensitas yang berasal dari 6 laser Visual Fault Locator yang dikopel menggunakan 1x8 splitter. Tanpa adanya kontrol fase, diperoleh hasil bahwa banyaknya laser yang menghasilkan intensitas terbesar adalah kombinasi 3 laser. Sedangkan, pada kombinasi 6 laser diperoleh daya yang lebih rendah dibandingkan daya 1 laser, hal ini menandakan bahwa kontrol fase menjadi sangat penting agar interferensi konstruktif dapat terjadi.
\end{abstract}

Kata kunci: laser dioda, metode side-by-side combining, interferensi konstruktif, material nonlinear 


\section{PENDAHULUAN}

Material nonlinear menjadi material kunci atas teknologi komunikasi dan informasi modern. Perkembangan dunia optoelektronik seperti ultrafast switching, modulasi informasi berkapasitas tinggi, gerbang logika berbasis optik, dan pandu gelombang pembagi daya adalah aplikasi langsung dari material nonlinear (Fushimi, 2014). Karakteristik utama material nonlinear adalah mengalami perubahan suseptibilitas optik seiring perubahan intensitas sumber cahaya yang merambat pada pandu gelombang optik. Perubahan suseptibilitas optik tersebut berpengaruh terhadap sifat optik dari suatu bahan seperti pada nilai indeks bias dan polarisasinya. Melalui pemanfaatan sifat nonlinearitas suatu material maka seseorang dapat dengan mudah merekayasa sifat optik sesuai kehendak (Handoko, 2006).

Dalam praktik pemanfaatan material nonlinear, adanya sumber cahaya memiliki peran sentral. Hal ini disebabkan oleh ampilfikasi intensitas sumber cahaya dapat menyebabkan munculnya efek nonlinear. Selama ini amplifikasi intensitas cahaya tersebut dilakukan melalui doped fiber amplifier (DFA). DFA bekerja berdasarkan pengalihan energi foton konvensional dari tingkatan energi sebuah atom maupun ion (kristalin). Sinyal lemah yang melewati medium aktif dalam DFA kemudian dicampur dengan sinyal foton pemompa, sehingga medium aktif tersebut akan menghasilkan cahaya emisi terangsang yang koheren dengan panjang gelombang sinyal (Katti, 2016). Emisi terangsang inilah yang menyebabkan perubahan intensitas daya sinar laser pada jalur keluaran DFA. Amplifikasi daya pada DFA bergantung pada dimensi panjang doped fiber, semakin panjang doped fiber-nya maka amplifikasi dayanya menjadi semakin besar. Salah satu material aktif yang memiliki kemampuan mengamplifikasi foton adalah Erbium $\left(\mathrm{Er}^{3+}\right)$, sehingga sistem penguat intensitas daya optik sering disebut dengan Erbium Doped Fiber Amplifier (EDFA) (Rudnitsky, 2011).

Harga EDFA di pasaran cukup mahal dan rancang bangun sistem penguatan optik EDFA juga memerlukan biaya yang sangat tinggi, termasuk pengadaan tools dan optikal instrument yang digunakan (Koos, 2009). Di Indonesia, selama ini rancang bangun EDFA dilakukan hanya sebatas simulasi (Pramono, 2000). Oleh karena itu, pada penelitian ini akan dirancang suatu alat yang mampu melakukan amplifikasi intensitas daya dengan biaya yang relatif ekonomis namun tetap memberikan performa yang optimum, yakni berbasis laser dioda dan menggunakan prinsip superposisi gelombang.

Intensity tunable laser (ITL) adalah laser yang mampu diatur daya keluarannya melalui arus listrik yang dikenakan (Pedrola, 2015). ITL pada umumnya hanya berjumlah satu laser yang telah memiliki rentang kontrol daya tertentu. Melalui prinsip superposisi gelombang, pada penelitian ini telah dianalisis pengaruh jumlah laser dioda terhadap amplifikasi daya intensity tunable laser, yang divariasikan sebanyak 1 hingga 6 buah laser dioda dan dikopel dengan 1x8 splitter.

\section{METODE PENELITIAN}

Adapun penelitian ini dilakukan menggunakan metode yang sesuai dengan diagram alir pada Gambar 1.

\subsection{Variabel Penelitian}

Terdapat dua variable bebas dari penelitian ini yakni banyaknya laser yang dikopel, dari 2 , 3, 4, 5, dan 6, dan besarnya arus listrik yang dikenakan pada laser dioda (berasal dari rangkaian tunable arus) dalam rentang 0-70 mA. Variabel kontrolnya adalah jenis laser dioda yang digunakan yakni laser visual fault locator dan ruang pengambilan data yang dijaga agar segelap mungkin sehingga tidak ada data intenstas lingkungan yang terbaca oleh optical 
power meter. Sedangkan variable terikatnya adalah intensitas laser yang terukur pada optical power meter.

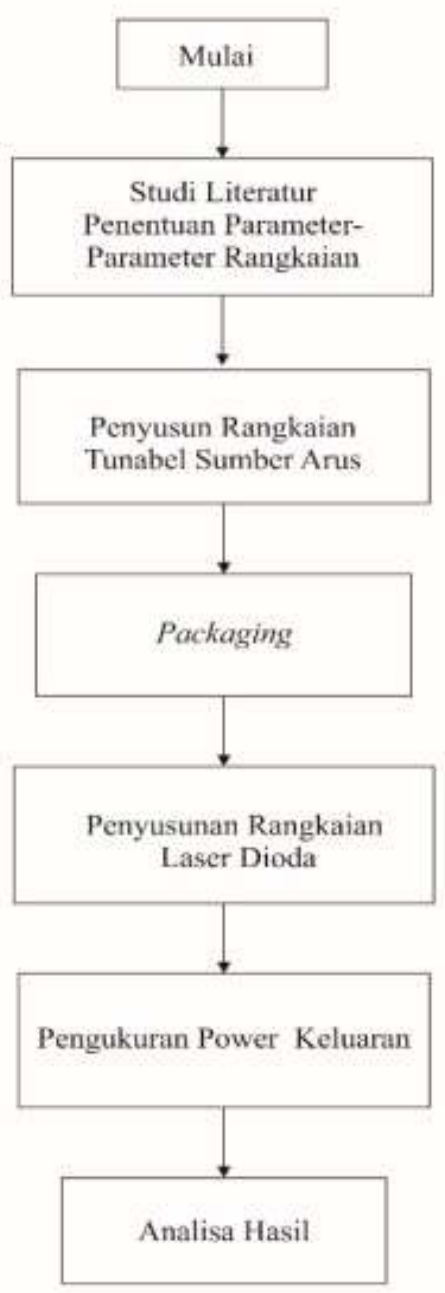

Gambar 1. Diagram alir penelitian

\subsection{Alat dan Bahan}

Adapun alat yang digunakan dalam penelitian ini adalah Optical Power Meter (OPM), Laser Visual Fault Locator, 1x8 Splitter, rangkaian pengatur arus yang dibuat sendiri, dan pemotong fiber. Sedangkan bahan yang diguanakan adalah fiber optik.

\subsection{Prosedur Penelitian}

Penelitian ini dilakukan secara eksperimental di Laboratorium Rekayasa Fotonika, Jurusan Teknik Fisika, Fakultas Teknologi Industri ITS, tahun 2017. Berikut adalah prosedur atau langkah kerja yang telah dilakukan dalam penelitian ini:

1. Daya output setiap laser diukur menggunakan Optical Power Meter.

2. Setiap penambahan laser yang dipasang pada 1x8 splitter, diukur daya output laser dengan variasi perubahan arus.

3. Langkah no 2 dilakukan untuk menganalisis 2,3,4,5 hingga 6 laser dioda yang merupakan bagian dari Visual Fault Locator. 


\section{Hasil dan Pembahasan}

Berdasarkan penelitian yang telah dilakukan, telah dibuat rangkaian pengatur arus untuk menjadi sumber daya pada laser dioda. Skema rangkaian listrik dari rangkaian pengatur arus ditunjukkan oleh Gambar 2. dan bentuk jadinya ditunjukkan oleh Gambar 3. Spesifikasi dari rangkaian pengatur arus tersebut disesuaikan dengan spesifikasi laser dioda, yakni tegangan yang dijaga konstan pada 3,5 Volt, dan arus yang dapat di-tunable pada 0-10 mA. Rangkaian pengatur arus tersebut kemudian disempurnakan dengan penambahan LCD yang ditunjukkan pada Gambar 4 dan dapat di tunable pada rentang arus 0-70 mA. Adapun hasil pengujian dari alat pengatur listrik yang diubah berdasarkan putaran pada potensiometer ditunjukkan oleh Gambar 5. Dari data hasil pengujian tersebut, grafik menunjukkan hasil yang mendekati linear sehingga dapat digunakan untuk men-tuning laser dioda.

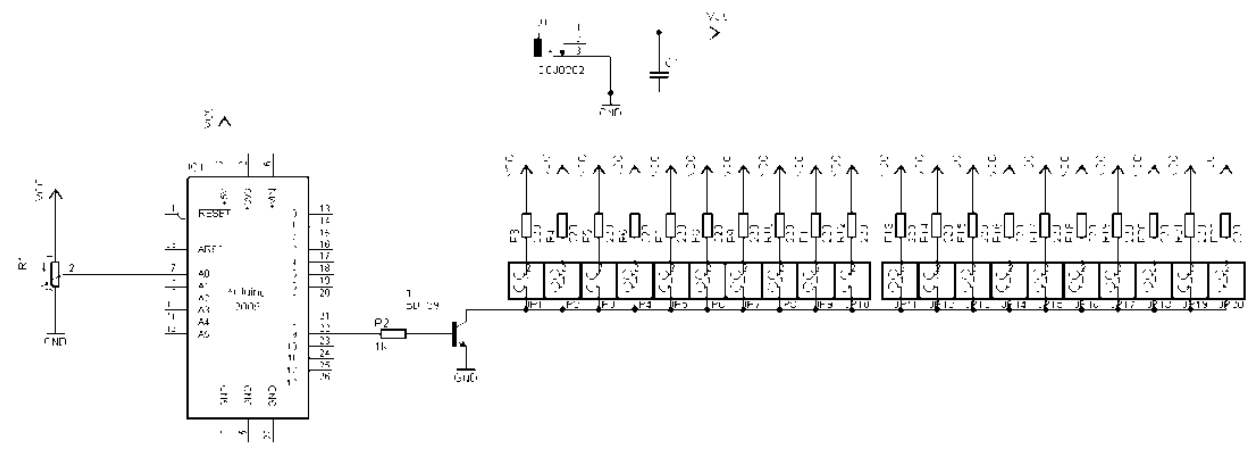

Gambar 2. Skema rangkaian pengatur arus listrik

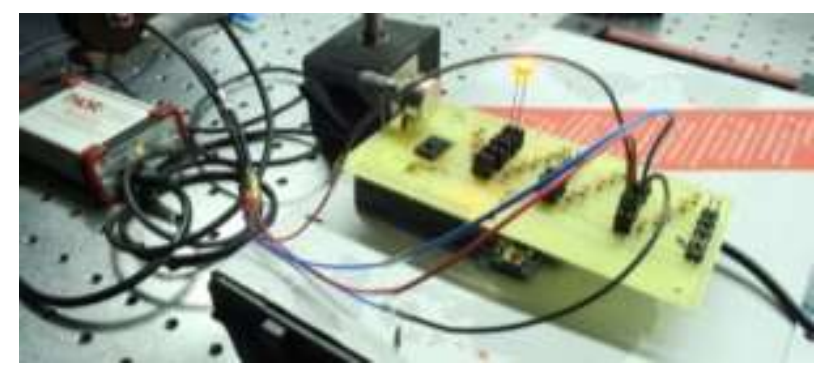

Gambar 3. Bentuk jadi rangkaian pengatur arus listrik

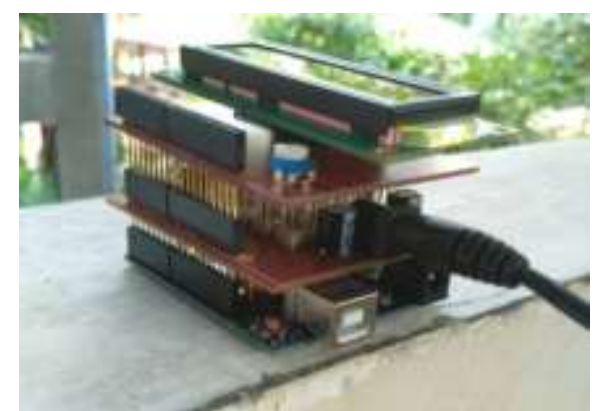

Gambar 4. Penyempurnaan rangkaian pengatur arus listrik yang dilengkapi LCD 


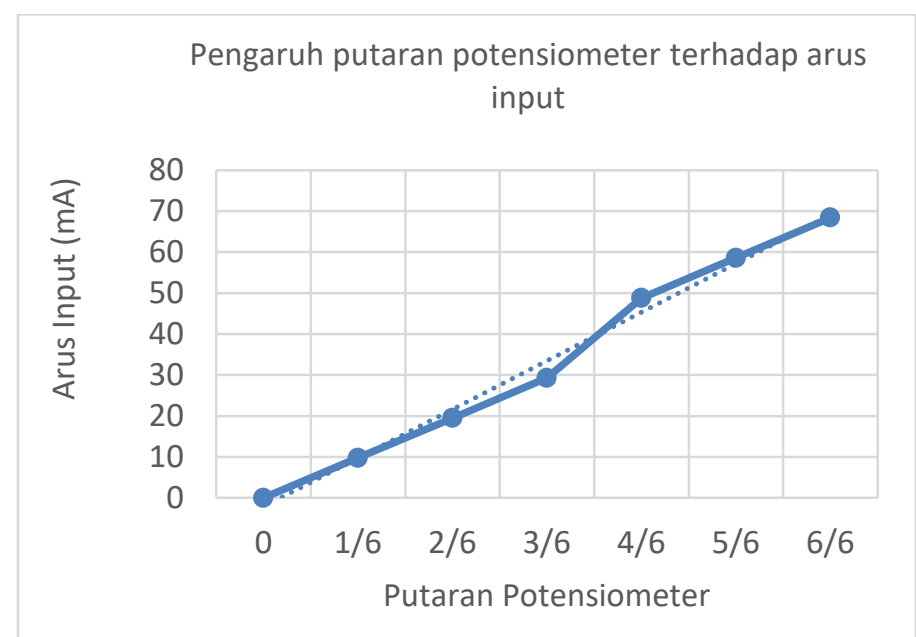

Gambar 5. Grafik pengaruh putaran potensiometer terhadap arus input

Rangkaian pengatur arus tersebut dipasangkan terhadap laser yang secara skema ditunjukkan oleh Gambar 6 tanpa adanya gain elements. Set-up peralatan tersebut menggunakan 1x8 splitter sebagai media untuk menggabungkan berkas dari beberapa laser dan disebut dengan metode side by side combining (Fan, 2005). Data hasil pengujian dari setup peralatan eksperimen tersebut ditunjukkan oleh Gambar 7.

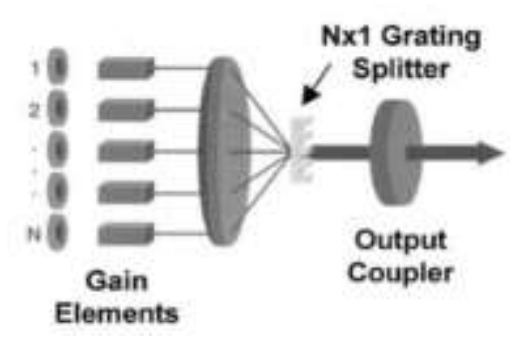

(a)

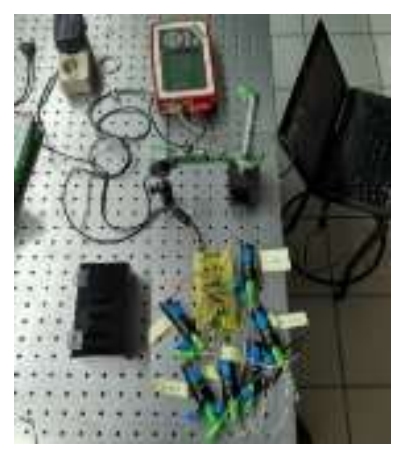

(b)

Gambar 6. (a) Set-up peralatan eksperimen (Fan, 2005) (b) Realisasi di laboratorium

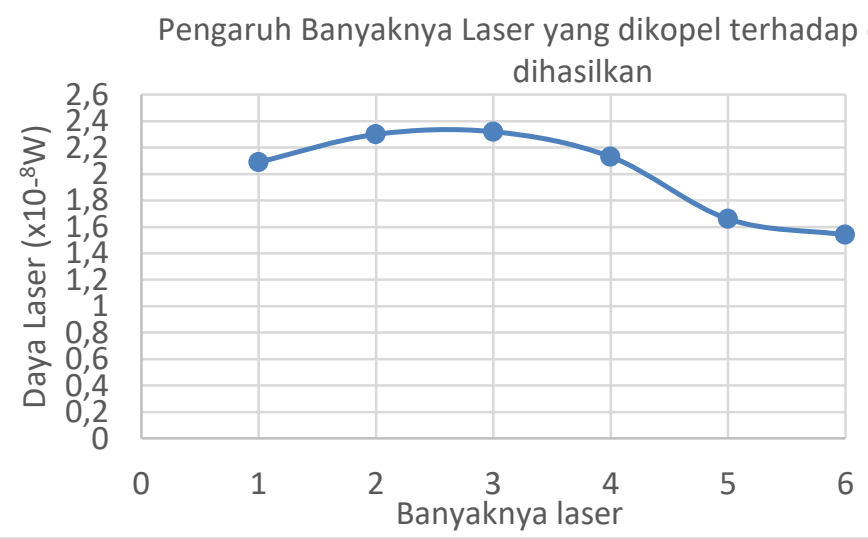

Gambar 7. Grafik pengaruh banyaknya laser yang dikopel terhadap daya yang dihasilkan

Gambar 7. menunjukkan bahwa banyaknya laser yang optimal untuk dikopel berjumlah 3 laser, menghasilkan daya output sebesar $23,7 \mathrm{nW}$. Pada penambahan laser ke-4 hingga ke-6 dayanya mengalami penurunan disebabkan oleh semakin besarnya peluang interferensi 
destruktif. Interferensi destruktif menyebabkan pelemahan amplitudo, padahal daya output bergantung kepada kuadrat dari nilai amplitudo. Terjadinya interferensi destruktif tersebut disebabkan oleh fase yang berbeda-beda dari setiap laser. Oleh karena itu, pengembangan penelitian pada topik ini dapat dilakukan dengan penambahan kontrol fase. Kontrol fase tersebut akan menyebabkan terjadinya interferensi konstruktif sehingga prinsip superposisi dapat terjadi.

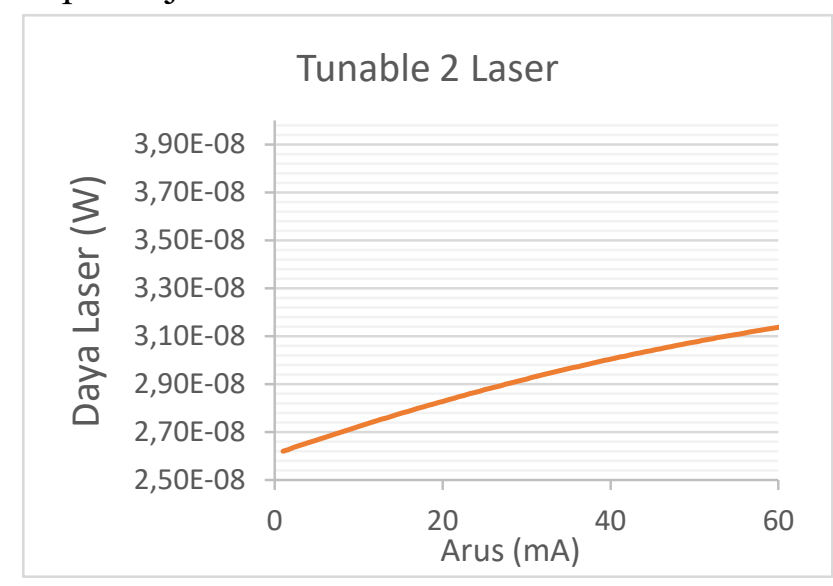

(a)

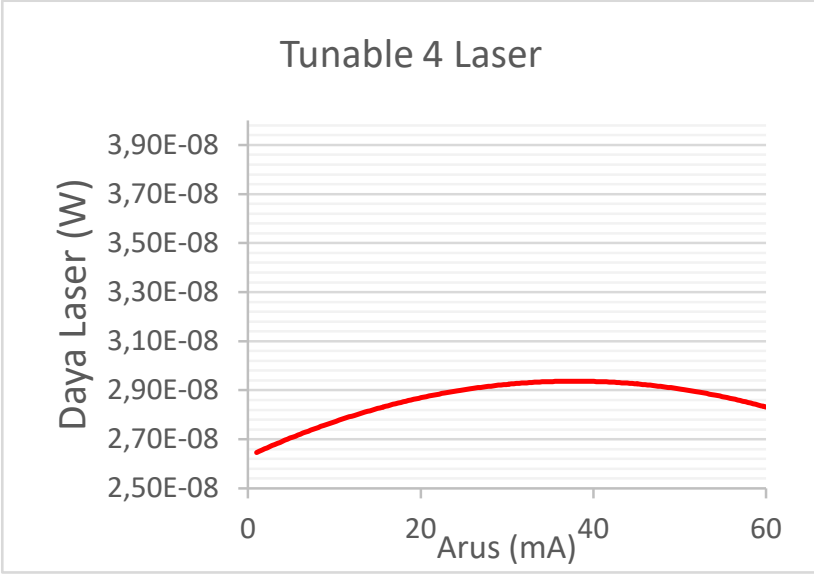

(c)

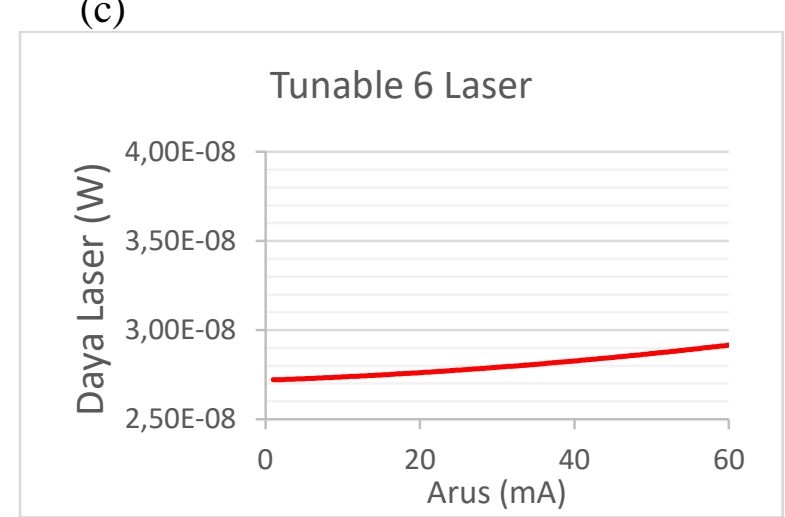

(e)

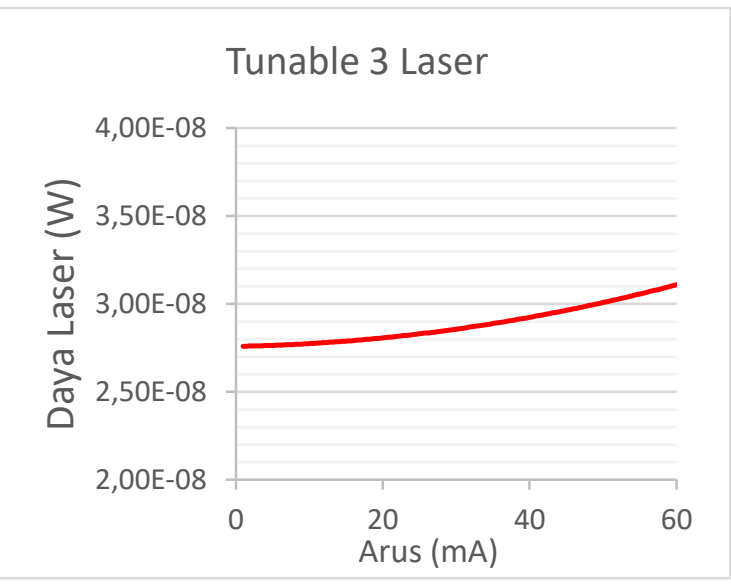

(b)

\section{Tunable 5 laser}

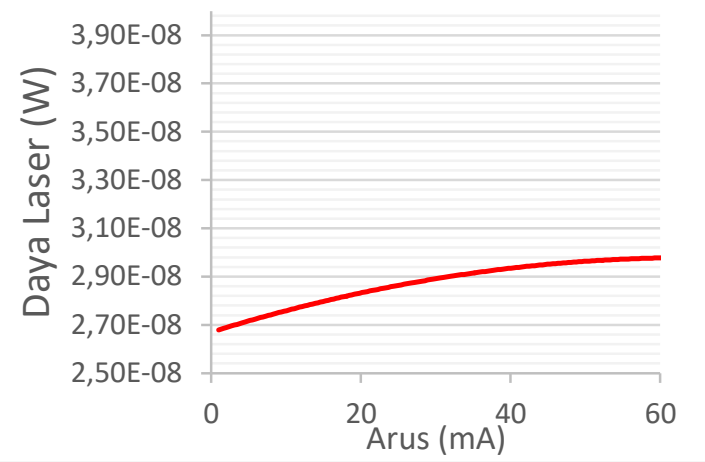

(d)

Gambar 8. Pengaruh arus listrik terhadap daya laser untuk setiap penambahan laser

Gambar 8 menunjukkan pengaruh perubahan arus listrik yang divariasikan menggunakan putaran potensiometer menunjukkan bahwa besar arus sebanding dengan besarnya daya laser yang terukur di optical power meter. Namun, hal yang sebaliknya terjadi pada susunan 4 
laser, semakin besar arus maka daya terukurnya menjadi semakin kecil. Hal ini disebabkan oleh interferensi destruktif. Tidak adanya kontrol fase menyebabkan daya optik saling melemahkan meskipun terjadi kenaikan arus.

\section{Kesimpulan}

Berdasarkan penelitian yang telah dilakukan, diperoleh hasil sebagai berikut:

a) Telah berhasil dibuat rangkaian pengatur arus dan pengukur daya masukan baik tanpa LCD dan dengan LCD yang diatur dengan potensiometer.

b) Daya output susunan laser sebanding dengan arus listrik yang dikenakan, namun tidak dapat dimodelkan secara matematis karena menghasilkan grafik yang berbeda-beda.

c) Jumlah laser dioda yang menghasilkan daya optimum adalah 3 laser dengan daya output sebesar 23,7 nW.

d) Sangat diperlukan pengontrol fase agar diperoleh interferensi konstruktif pada saat mengkombinasikan laser, jika tidak maka daya 6 laser akan lebih kecil dibandingkan denga daya 1 laser.

\section{Daftar pustaka}

Fan, T.Y., (2005). Laser beam combining for high-power, high-radiance sources. IEEE Journal of Selected Topics in Quantum Electronics 11, 567-577. doi:10.1109/JSTQE.2005.850241

Fushimi, A. and T. Tanabe. (2014). All-optical logic gate operating with single wavelength. Optics Express, vol. 22, no. 4, p. 4466, Feb. 2014.

Handoko, N. R. B., Firdausi, K. S., dan Setiawati, E. 2006 Penentuan Nilai Koefisien Linier Magneto Optik Material Transparan Menggunakan Interferometer Michelson. [serial online] http://eprints.undip.ac.id/2517/1/Penentuan_Nilai_koefisien_Linier_Magneto

_Optik__Material_Transparan_Menggunakan_Interferometer_ Michelson.pdf [8 Oktober 2017].

Katti, R. and S. Prince. 2016. All Optical new $3 \times 3$ reversible logic gate using MachZehnder Interferometer," Optical and Quantum Electronics, vol. 48, no. 1.

Koos, C. et al. 2009.All-optical high-speed signal processing with silicon-organic hybrid slot waveguides. Nature Photonics, vol. 3, no. 4, pp. 216-219.

Pedrola,L.G..Beam Propagation Method: For Design of Optical Waveguide Devices. Chichester, West Sussex: John Wiley \& Sons, Inc, 2015.

Pramono, Y.H, Geshiro, M., Kitamura, T., dan Sawa, S. (2000). Self-switching in Crossing waveguide With Three Channel Cositing of Nonlinier Material. IEICE Trans. Electron, Vol. E82-C, no. 1, pp 111-118.

Rudnitsky, A. et al., "All-optical integrated micro logic gate. (2011). Microelectronics Journal, vol. 42, no. 2, pp. 472-476, Feb. 